\title{
What Else Can Music Preferences do? A Commentary on Clark and Giacomantonio
}

\author{
ALEXANDRA LAMONT \\ Keele University
}

\begin{abstract}
This commentary considers the uses to which information about music preferences can be put, considering the findings from Clark and Giacomantonio (2015) and other related studies of music preferences. It focuses on three areas. Firstly, the ways in which music preferences can be, and have been, studied are critically examined. Secondly, the factors and variables to which music preferences have been linked are investigated, exploring the nature and direction of this relationship. Finally, the specific findings of Clark and Giacomantonio in relation to music and empathy are critically evaluated. Further research is required before firm implications about the direction of influences between music preferences and other variables can be drawn.
\end{abstract}

Submitted 2014 October 16; accepted 2014 November 3.

KEYWORDS: music preferences, prosocial behavior, empathy, identity, theory

MUSIC preferences are held to provide privileged information which can explain various non-musical aspects of behavior. In particular, knowing someone's musical preferences has been shown to provide insights into the personality characteristics of the person holding such preferences, their gender, their political beliefs, and a host of other social variables (Rentfrow \& Gosling, 2006, 2007; North \& Hargreaves, 2007a, 2007b, 2007c), and thus preferences can be used to explain features of social life such as friendships and dating (Selfhout, Branje, ter Bogt, \& Meeus, 2009; Rentfrow \& Gosling, 2006).

This commentary explores the issue of precisely what knowledge about music can reliably inform us about, reflecting on the specific recent findings of Clark and Giacomantonio (2015) demonstrating links between music preferences and levels of empathy in young adults. I critically examine some of the assumptions made in this and other research papers, first in relation to the ways in which music preferences are studied and what that can inform us about, and secondly in relation to the complexity of an individual's social make-up and interactions with others.

\section{RESEARCHING MUSIC PREFERENCES}

The field of music preferences is itself highly contested and before considering the validity of the results obtained in relation to any other factors, close investigation of the methods used to generate data is essential. The empirical study of music preferences has a long and complex pedigree (Greasley \& Lamont, 2015), with a weight of research being dedicated to the construction and refinement of scales of music preference. From Litle and Zuckerman's Music Preference Scale developed in 1986, more recent work has developed validated measures, the most used being Rentfrow and Gosling's Short Test of Music Preferences (STOMP; 2003). This begins from the finding that listeners seem to be most familiar with styles at a broad style level. The initial STOMP contained 14 broad styles, and listeners' responses clustered into four preference dimensions termed "reflective and complex" (classical, jazz, blues, folk), "intense and rebellious" (alternative, rock, heavy metal), "upbeat and conventional" (country, pop, religious, soundtracks), and "energetic and rhythmic" (rap/hip-hop, soul/funk, dance/electronica). Rentfrow and Gosling also identified coherent patterns of musical attributes which defined each dimension: for instance, reflective and complex music is associated with slow tempos, very little singing, lyrically and musically higher levels of complexity, positive and negative affect, and low energy level, while intense and rebellious music is associated with faster tempos, more singing, moderate levels of complexity, lower levels of positive affect, and higher levels of negative affect and energy. The STOMP has been validated 
with different samples and participants from different cultural backgrounds (e.g. Langmeyer, GuglhörRudan, \& Tarnai, 2012).

Other researchers working along similar lines have found similar but not always identical patterns and numbers of dimensions in music preference to Rentfrow and Gosling: Dunn, de Ruyter, and Bouwhuis (2012) started with 16 styles and ended with 6 dimensions, while George, Stickle, Rachid, and Wopnford (2007) included 30 styles and 8 dimensions. In parallel to attempts to generate standardized validated measures, other researchers have explored music preferences using surveys without psychometrically tested scales. For example, in their large-scale correlational survey research with over 2000 participants, North and Hargreaves $(2007 \mathrm{a}, 2007 \mathrm{~b}, 2007 \mathrm{c})$ initially included a list of 35 musical styles and then only analyzed those styles selected by more than 50 participants, leaving a list of 24 (opera, country and western, jazz, rock, current chart pop, soul, classical, disco, dance house, hip-hop/rap, musicals, blues, sixties pop, indie, adult pop/MOR, DJ-based music, other pop musical styles, and "other" musical styles). This lack of systematic approaches to measuring musical preferences is certainly challenging for any socialpsychological approach to the topic, making it very difficult to compare findings across research groups and also across time (given that the precise categories that are relevant to a given population are subject to change and development). Rentfrow and Gosling's approach in developing and testing the STOMP was intended to remove the need for style labels which, evidence from other research suggests, participants often find problematic when thinking about their own musical tastes.

In their study, Clark and Giacomantonio propose an extension to Rentfrow and Gosling's approach, including work by Leung and Kier (2008) who claimed to have provided the most comprehensive list of genres to date, and develop their own Music Preference Factor Scale, which was used alongside the STOMP. They claim that the MPFS shows strong face- and criterion-related validity. Where they diverge from the original research using these scales is that they classify individuals as falling into one of the four musical styles on the basis of the weight of their preferences, taking the highest scoring of the four factors to be representative of the totality of the individual's music preferences. The same approach is taken with the data collected using the STOMP, with some minor differences in the proportions across measures for the same participants. However, when comparing their preference ratings with empathy scores, Clark and Giacomantonio use bivariate correlations based on the extent of preference each individual shows for the four factors, enabling a more sophisticated use of the categorization approach such that individuals' preferences for all types of music can be more adequately reflected in the data.

One key challenge which can be leveled at the psychometric approach to music preferences is what exactly it is that is being captured. While music is often cited as being used by adolescents in particular as a badge of identity (North \& Hargreaves, 1999), like any other, the badge is a shorthand cue. What is perceived by others is their own stereotypes and reduction of the complexity that underlies that cue. The cue of a heavy metal fan, to take a clear example, typically invokes a stereotype of a pale-skinned white male teenager with long hair, makeup, piercings, or tattoos, who might demonstrate elevated levels of depression, aggression, and anti-social behavior. However, other musical styles are less obvious. What about the teenage classical music fan? Or the Country \& Western fan, rarely found outside the United States? Do the many who have strong preferences for a variety of musical styles simply wear many badges, and how does an observer make sense of their taste? And what about those who reject style labels entirely as inadequate characterizations of the complexity and subtlety of their music preferences? "Music preferences" cannot be summed up using neat categorizations, but are often complex and shifting constructions of identity (Greasley, Lamont, \& Sloboda, 2013).

\section{WHAT CAN MUSIC PREFERENCES REALLY DO, AND WHY?}

The literature provides a wealth of evidence on the links that can be found between music preferences and personality, stretching back to the original work of Litle and Zuckerman (1986). For instance, preference for rock music is correlated with high levels of sensation-seeking, preference for popular music associated with high levels of extraversion, and broad music preferences are associated with openness to experience (Rawlings \& Ciancarelli, 1997). Most of this research suggests that personality is the predictor variable, since personality is a long-lasting individual difference factor which might guide participants into particular choices about friendship, preferred activities, and lifestyle features such as music. Some studies have used music preferences as a predictor and asked participants to make judgments based on that about personality (e.g. Rentfrow \& Gosling, 2006), with reasonable levels of success. Music preferences have also been linked to other lifestyle choices, beliefs, and attitudes (e.g. North \& Hargreaves, 2007a, 2007b, 2007c), and 
Clark and Giacomantonio's study provides more evidence in this line of research of connections between the types of music liked by participants and their levels of empathy.

However, all that music preferences, when reduced to labels as in the reductionist approach, can "do" in terms of predictive power is to operate at a fairly basic level of sophistication. At this level it is possible to generalize, to stereotype, and to make reasonable assumptions based on limited information. It is also possible to find connections between music preferences and many other variables such as personality, beliefs, and attitudes. For example, studies indicate that fans of indie, hip-hop/rap, soul, and jazz are apparently more likely to believe that the UK should join the Euro, while fans of musicals, chart pop, country \& Western, and adult pop are least likely to (North \& Hargreaves, 2007a). To give another example, opera fans wash their hair least often, while DJ-based music fans wash their hair most often (North \& Hargreaves, 2007c). Or, as Clark and Giacomantonio illustrate (2015), small, non-significant relationships can be found between preference for different kinds of music and levels of empathy: especially for men, preference for reflective and complex music and for intense and rebellious music is linked with higher levels of empathy, while preference for upbeat and conventional music is linked with lower levels of empathy.

While this research often concedes that there may be certain underlying common factors ("putative social status" is mentioned in North \& Hargreaves, 2007c, which relates to the variables of travel, money, education and employment), their design does not enable these hidden mediating variables to be identified nor their effects tested. What is often missing in this research is a theoretical explanation for why such relationships should exist. Whether the findings really inform us about an individual in a meaningful way is somewhat debatable. While Rentfrow and Gosling (2006) found music was one of the most common topics when getting to know a stranger, they also found that the incidences of music-related conversation amongst acquaintances, friends, and those in committed relationships dropped, and our own research has shown many couples have quite different music tastes (Greasley, 2008). To draw on Kahneman's concepts (2011), the labeling and use of music preferences in these studies provide a way of engaging our System 1, the cognitive mechanism that allows us to make rapid but often uncritical judgments about situations or people; Kahneman cautions that System 2, our conscious, reasoning self, while underused, is essential for fully engaging with the complexities of the environment and, as he suggests, often "has the last word" (p. 25). Shorthand can be useful, yet as we move beyond assumptions, stereotypes, and zero-order acquaintances further into the complexities of individuals and their behavior over time, the utility and explanatory power of music preferences seems to decline.

\section{MUSIC PREFERENCES AND EMPATHY}

In their article, Clark and Giacomantonio (2015) review relevant evidence suggesting firstly that empathy is a feature which varies, i.e. that levels of empathy are not consistent from person to person, and secondly that there is a developmental trajectory that can be identified, with a decline in prosocial behaviors in early adolescence followed by an increase in late adolescence (see also Clark \& Giacomantonio, 2013). They intended to explore both these factors in their study, although unfortunately their final sample consisted only of participants aged 18 and above, which they divided into two age groups: those aged 18-24, and those aged 25 and older (the rationale for the cut-off is not stated). This considerably limits their ability to address the initial hypotheses about age-related change and development in empathy levels which concerned transitions from early to late adolescence. Instead, new speculations are generated about decreasing empathy in adulthood compared with the flourishing found in late adolescence, based on the finding in the study that the older group showed lower levels of empathy.

What is demonstrated in their analysis is that there are some connections between empathy and music preferences, particularly for males and particularly for the cognitive rather than affective elements of empathy. Younger males showed higher levels of empathy if they liked reflective and complex music and intense and rebellious music. Some suggestions are made here for the influence of lyrics, since lyrics in those two styles reflect broader emotions as compared to the more personal, individualistic, or mundane lyrics that dominate upbeat and conventional music. These speculations require further investigation. The direction of this influence also remains to be established. There is face validity in the suggestions from research by Greitemeyer (2009a, 2009b) that listening to pro-social lyrics might promote empathy, thus indicating that music choices directly influence other aspects of behavior; this seems far more plausible than the more spurious connections cited earlier between aspects of music preference and behaviors such as hair-washing or employment. 
Clark and Giacomantonio (2015) begin and end their paper by considering the implications of listening to different types of music for aspects of mental health, working on the assumption that the music behavior is responsible for the other outcomes. However, Baker and Bor (2008), reviewing evidence on adolescent music preferences and mental health, found music preference to be an outcome rather than a cause of emotional vulnerability: adolescents experiencing emotional difficulties such as low self-esteem or anger were more likely to gravitate towards heavy metal or rap music. Further work is required to explore the direction of any potential relationships in more depth, and to generate theoretical explanations to explain these. When considering the effects of lyrics, research also needs to account for findings that while some listeners are extremely attuned to the lyrics of the music they listen to, others pay far less attention (e.g. Greasley, 2008).

\section{CONCLUSION}

In summary, caution needs to be applied when considering findings that seem to suggest links between music preferences and other aspects of behavior. It is always important to examine how preferences are being assessed, what theoretical explanations can be put forward for potential influences in one or both directions, and to consider the existence of hidden mediating or moderating variables which may explain these relationships better than music. Music preferences often serve as either a shorthand for, or an expression of, underlying social or psychological attitudes and behaviors, and in order to understand these more fully, research has to attempt to do justice to the complexity of both the attitudes and behaviors under investigation, and the music preferences that are linked to them.

\section{REFERENCES}

Baker, F., \& Bor, W. (2008). Can music preference indicate mental health status in young people? Australasian Psychiatry, 16(4), 284-288.

Clark, S. S., \& Giacomantonio, S. G. (2013). Music preferences and empathy: Toward predicting prosocial behavior. Psychomusicology: Music, Mind, and Brain, 23(3), 177-186.

Clark, S. S., \& Giacomantonio, S. G. (2015). Toward predicting prosocial behavior: Music preference and empathy differences between adolescents and adults. Empirical Musicology Review, 10(1), 50-65.

Dunn, P. G., de Ruyter, B., \& Bouwhuis, D. G. (2012). Toward a better understanding of the relation between music preference, listening behaviour, and personality. Psychology of Music, 40(4), 411-428.

George, D., Stickle, K., Rachid, F., \& Wopnford, A. (2007). The association between types of music enjoyed and cognitive, behavioral, and personality factors of those who listen. Psychomusicology, 19, 3256.

Greasley, A. E. (2008). Engagement with music in everyday life: An in-depth study of adults' musical preferences and listening behaviours. Unpublished doctoral dissertation, Keele University, UK.

Greasley, A. E., \& Lamont, A. (2015, in press). Musical preferences. In S. Hallam, I. Cross, \& M. Thaut (Eds.), The Oxford handbook of music psychology ( $2^{\text {nd }}$ edition). Oxford: Oxford University Press.

Greasley, A. E., Lamont, A., \& Sloboda, J. A. (2013). Exploring musical preferences: An in-depth qualitative study of adults' liking for music in their personal collections. Qualitative Research in Psychology, 10(2), 402-442.

Greitemeyer, T. (2009a). Effects of songs with prosocial lyrics on prosocial thoughts, affect, and behavior. Journal of Experimental Social Psychology, 45(1), 186-190.

Greitemeyer, T. (2009b). Effects of songs with prosocial lyrics on prosocial behavior: Further evidence and a mediating mechanism. Personality and Social Psychology Bulletin, 35(11), 1500-1511. 
Kahneman, D. (2011). Thinking, fast and slow. London: Allen Lane.

Langmeyer, A., Guglhör-Rudan, A., \& Tarnai, C. (2012). What do music preferences reveal about personality? A cross-cultural replication using self-ratings and ratings of music samples. Journal of Individual Differences, 33(2), 119-130.

Litle, P., \& Zuckerman, M. (1986). Sensation seeking and music preferences. Personality and Individual Differences, 7, 575-578.

Leung, A., \& Kier, C. (2008). Music preferences and civic activism of young people. Journal of Youth Studies, 11(4), 445-460.

North, A. C., \& Hargreaves, D. J. (1999). Music and adolescent identity. Music Education Research, 1(1), 75-92.

North, A. C., \& Hargreaves, D. J. (2007a). Lifestyle correlates of musical preference: 1. Relationships, living arrangements, beliefs, and crime. Psychology of Music, 35(1), 58-87.

North, A. C., \& Hargreaves, D. J. (2007b). Lifestyle correlates of musical preference: 2. Media, leisure time, and music. Psychology of Music, 35(2), 179-200.

North, A. C., \& Hargreaves, D. J. (2007c). Lifestyle correlates of musical preference: 3. Travel, money, education, employment and health. Psychology of Music, 35(3), 473-497.

Rawlings, D., \& Ciancarelli, V. (1997). Music preference and the five-factor model of the NEO Personality Inventory. Psychology of Music, 25(2), 120-132.

Rentfrow, P. J., \& Gosling, S. D. (2003). The do re mi's of everyday life: Examining the structure and personality correlates of music preferences. Journal of Personality and Social Psychology, 84(6), 12361256.

Rentfrow, P. J., \& Gosling, S. D. (2006). Message in a ballad: The role of musical preferences in interpersonal perception. Psychological Science, 17(3), 236-242.

Rentfrow, P. J., \& Gosling, S. D. (2007). The content and validity of stereotypes about fans of 14 music genres. Psychology of Music, 35(2), 306-326.

Selfhout, M. H. W., Branje, S. J. T., ter Bogt, T. F. M., \& Meeus, W. H. J. (2009). The role of music preferences in early adolescents' friendship formation and stability. Journal of Adolescence, 32(1), 95-107. 